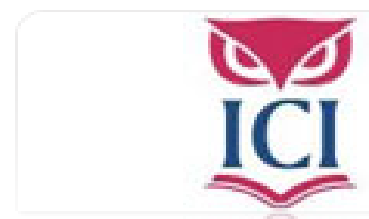

IUS. Revista del Instituto de Ciencias Jurídicas de Puebla A.C.

ISSN: 1870-2147

revista.ius@hotmail.com

Instituto de Ciencias Jurídicas de Puebla A. C.

México

Rodríguez Martínez, Yuriria A.

Los derechos sexuales de las y los jóvenes en el contexto jurídico nacional e internacional IUS. Revista del Instituto de Ciencias Jurídicas de Puebla A.C., núm. 20, 2007, pp. 211-243 Instituto de Ciencias Jurídicas de Puebla A. C.

Puebla, México 


\section{LOS DERECHOS SEXUALES DE LAS Y LOS JÓVENES EN EL CONTEXTO JURÍDICO NACIONAL E INTERNACIONAL}

Yuriria A. Rodríguez Martínez*

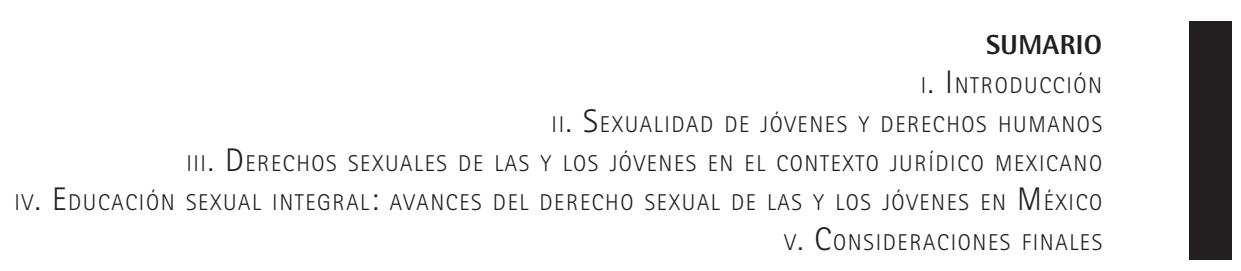

\section{RESUMEN}

El presente artículo aborda las referencias juridicas nacionales e internacionales que fundamentan el debate sobre los derechos sexuales. Sobre esta intención se relacionan los documentos más importantes que han abordado el tema y que van desde la Conferencia sobre Derechos Humanos de Teherán de 1968, en donde se estableció por primera vez el derecho de las parejas para decidir el número de hijos y su espaciamiento, hasta la Convención sobre la Eliminación de todas las formas de Discriminación contra la Mujer de 1979, que fue el primer tratado internacional que aseguró la igualdad de acceso a los servicios de planificación familiar. Profundiza en los avances en materia de educación sexual en el pais como derecho y hace

\section{ABSTRACT}

The present article approaches the national and international juridical references that base the debate on the sexual rights. On this intention is related the most important documents that have approached the topic and that they go from the Conference it has more than enough Human rights of Teheran 1968, where settled down the right of the couples for the first time to decide the number of children and its spacing, until the Convention on the Elimination in all the ways of Discrimination against the Woman of 1979, that the first international treaty that assured the access equality to the services of family planning was. It approaches in the advances as regards sexual education in the

* Doctora en ciencias sociales, en la especialidad mujer y relaciones de género, por la Universidad Autónoma Metropolitana, Unidad Xochimilco. 
algunas consideraciones en cuanto a la necesidad de desarrollar más amplia y específicamente el marco jurídico mexicano vigente y la construcción de más herramientas jurídicas que posibiliten la protección de los derechos humanos en el campo de la sexualidad. La autora concluye que el derecho sexual a la educación sexual científica, confiable y laica, en México se ha impulsado y desarrollado en un trabajo colaborativo interinstitucional entre organizaciones gubernamentales, civiles y académicas, especialistas en el rubro. country like right and he makes some considerations as for the necessity of developing wider and specifically the Mexican norms and the construction of more juridical tools that facilitate the protection of the human rights in the field of the sexuality. The author concludes that the sexual right to the scientific, reliable and lay sexual education, in Mexico has been impelled and developed in a collaborative work among government, civil and academic organizations, specialists in the item.

El ser cada una/o sujetas y sujetos de derecho lleva implícito el respeto hacia las demás personas, es decir, podemos ejercer nuestras libertades y garantías individuales en tanto no violentemos el derecho de las y los demás. Ninguna persona debe atentar contra nuestros derechos.

Cartilla de los Derechos Sexuales de las y los Jóvenes, Comisión Nacional de los Derechos Humanos y más de 80 organizaciones civiles**

\section{INTRODUCCIÓN}

El presente artículo tiene el objetivo de establecer las referencias jurídicas nacionales e internacionales que fundamentan el debate sobre los derechos sexuales de las y los jóvenes en México. Para ello, resulta necesario delinear las ideas que fundamentan a las sexualidades de las y los jóvenes como un campo de derechos humanos en el que se condicionan y determinan diversas posibilidades de la configuración de los individuos como

** Publicada en enero de 2003 como parte de la Campaña Nacional por los Derechos Sexuales de las y los Jóvenes, que impulsó la Comisión Nacional de los Derechos Humanos y más de 80 organizaciones civiles de todo el país dedicadas a la defensa y promoción de estos derechos. Véase en http://infouam. blogspot.com/2005/03/cartilla-de-los-derechos-sexuales-de.html [visitada el 20 de junio de 2007]. 
sujetos de deseo, pero también de derechos. Particularmente se profundiza en los avances en materia de educación sexual en el país, siendo éste un derecho sexual de las y los jóvenes del cual se cuenta con diversas fuentes del derecho que lo sustentan y que han permitido desarrollarlo de alguna manera como parte de las políticas públicas educativas. Finalmente, se hacen algunas consideraciones en cuanto a la necesidad de desarrollar más amplia y específicamente el marco jurídico mexicano vigente y la construcción de más herramientas jurídicas que posibiliten la protección de los derechos humanos en el campo de la sexualidad de las y los jóvenes, y el correspondiente ejercicio de sus derechos sexuales, indispensable para atender las complejas problemáticas que enfrentan las y los jóvenes, como son los embarazos no deseados y los abortos inducidos en condiciones de riesgo, así como la transmisión del VIH/SIDA y otras infecciones de transmisión sexual.

La articulación del debate de la sexualidad humana, la salud y la reproducción, como parte de los ámbitos de protección de los derechos humanos para el desarrollo social y poblacional, derivada de los consensos internacionales de la Conferencia Internacional de Población y Desarrollo de El Cairo en 1994 y la iv Conferencia Internacional de la Mujer de Beijing en 1995, dio paso a la propuesta de derechos reproductivos y derechos sexuales, derechos de tercera generación, cuya definición ha avanzado en debates nacionales e internacionales con más claridad en lo que respecta a lo reproductivo, integrándose propuestas específicas de leyes, normas y programas de políticas públicas que pretenden promover y garantizar el derecho a decidir el número y espaciamiento de los hijos y a tener los medios necesarios para la planificación familiar y la anticoncepción, la protección de la salud materna y perinatal y el derecho a la atención de calidad durante el embarazo, el parto y puerperio previniendo así la muerte materna, entre otros. Estos avances han sido parte del recorrido histórico de la política de población que en México se inició en términos jurídicos en la década de los años setenta del siglo pasado con la promulgación de la Ley General de Población y la creación del Consejo Nacional de Población, abriendo camino para la posterior integración de los acuerdos internacionales de la década de los noventa, relativos a los compromisos adquiridos por el gobierno mexicano en El Cairo y Beijing, a través de la creación del Programa Nacional de Salud Reproductiva y Planificación Familiar 1995-2000, con la respectiva Dirección General de Salud Reproductiva de la Secretaría de Salud en 1995. 
En cuanto a los derechos sexuales, la apertura de los debates en la academia, las instituciones de servicios y la opinión pública en México se ha derivado principalmente de la necesidad de salud pública en términos de atender la pandemia del VIH/SIDA, desarrollar programas y acciones para la prevención y para garantizar un tratamiento de calidad a quienes viven con ese padecimiento. Además, el avance en la incorporación de algunas garantías de derechos relativos con la sexualidad, las prácticas y preferencias sexuales, se evidencia en el contexto jurídico mexicano con la Ley de Sociedad de Convivencia del Distrito Federal, promulgada en noviembre de 2006, y el Pacto Civil de Solidaridad del estado de Coahuila incorporado al Código Civil de ese estado de manera oficial en enero de 2006.

Específicamente, el derecho a la educación sexual como derecho sexual de las y los jóvenes se avanzó en México a partir de los compromisos internacionales adquiridos por el gobierno en El Cairo 1994 y Beijing 1995. En el sexenio 1994-2000 el Estado mexicano integró algunos contenidos en asignaturas y libros de texto de primaria y secundaria a través de la Secretaría de Educación Pública. Además, impulsó e implantó programas de atención a la salud reproductiva para adolescentes y jóvenes en las instancias de salud pública del país, incluyendo propuestas de acciones específicas para la educación sexual integral de las y los jóvenes mexicanos. En el nivel de educación primaria, desde 1998 se incluyeron algunos contenidos de información y educación sexual en los libros de texto de $5^{\circ}$ y $6^{\circ}$ grado, y en el nivel de secundaria se establecieron contenidos como parte de la currícula de la materia "Formación cívica y ética". Éstos son los avances más recientes, pero en México la educación sexual comenzó a integrarse en las escuelas y los libros de texto desde 1974, cuando el gobierno tomó la seria tarea de prevenir los embarazos entre adolescentes. La política pública dirigida a la reducción de embarazos en adolescentes ha obtenido resultados positivos teniendo una disminución importante del número de embarazos en esa población en los últimos treinta años.

Los avances en materia de información y educación sexual constituyen una muestra importante y clara de los avances en el marco jurídico mexicano en torno a los derechos sexuales de las y los jóvenes. Sin embargo, éste es sólo un derecho sexual que no se puede separar de otros derechos sexuales de las y los jóvenes, como son el derecho a la autodeterminación en todo lo relacionado con el cuerpo y la sexualidad, el derecho a disfrutar de la vida sexual, a la manifestación pública de los afectos, decidir con quién compartir la vida y la sexualidad, al respeto de la intimidad y la vida 
privada, a vivir una sexualidad libre de coerción y de violencia, libre de discriminación, a la libertad reproductiva, la igualdad de oportunidades y la equidad, así como a servicios de salud sexual y salud reproductiva de calidad y a participar en la elaboración, planeación y evaluación de las políticas públicas sobre sexualidad para jóvenes.

\section{Sexualidad DE Jóvenes Y derechos humanos}

Como se ha demostrado en diferentes estudios, la sexualidad es parte de la vida de los seres humanos, ${ }^{1}$ y como tal forma parte de la convivencia social en tanto cada cultura y sociedad define sus reglas para ejercer ciertas prácticas y prohibir otras. La sexualidad humana es una necesidad vital para la procreación de la humanidad y las formas de satisfacerla se construyen e instituyen históricamente en la convivencia sociocultural. Sin embargo, los estudios referidos a la sexualidad han demostrado que los seres humanos no sólo ejercen su sexualidad con fines de procreación. La sexualidad es una cualidad de los seres humanos y con ella se ejercen distintos tipos de relaciones, como las afectivas y de poder. Así, las conductas y prácticas sexuales generalmente tienen una variedad de funciones y fines como las de satisfacer necesidades afectivas, de comunicación, de relacionarse, de confirmación de identidades, a veces de sometimiento. ${ }^{2}$

La experiencia sexual de cada ser humano depende de su propia historia y sus condiciones de vida en cada caso. Por lo anterior, cuando se habla de sexualidad, se debe tener presente que existen diversas prácticas así como circunstancias y fines con que se realizan o no, con sus diferentes significados y valoraciones constituidas desde la subjetividad de los individuos en el contexto social histórico y cultural en el que viven. La sexualidad, como lo muestra Michael Foucault, es una construcción social

\footnotetext{
${ }^{1} \mathrm{Al}$ respecto hay un sinnúmero de investigaciones y desarrollos teóricos en las ciencias sociales. Véase por ejemplo una colección de lecturas referidas a la sexualidad como parte fundamental de la convivencia social en Jeffrey Weeks, Janet Holland y Matthew Waites, Sexualities and Society. A reader, United Kindom, Polity Press, Cambridge, 2003. También véanse estudios en México en esta materia realizados desde la antropología social, como por ejemplo, la revista Desacatos. Revista de Antropología Social, No. 6, Primavera-Verano 2001, que contiene artículos de investigaciones realizadas en México como la de Gabriela Rodríguez, "Perdiendo los estribos. Emociones y relaciones de poder en el cortejo". 0 las realizadas desde la psicología social, como la de Ana Amuchástegui, Virginidad e iniciación sexual en México. Experiencias y significados, Edamex-Population Council, México, 2001.

${ }^{2}$ El estado del arte respecto a la investigación sobre sexualidad en México y las evidencias de los diferentes significados y prácticas que involucra este ámbito del ser humano se puede revisar en Ana Luisa Liguori e lvonne Szasz, "La investigación sobre sexualidad en México", en la revista Perinatología y Reproducción Humana, Vol. 10, No. 2, abril-junio, 1996.
} 
e histórica en la que se producen y definen relaciones de poder, ${ }^{3}$ mismas que delimitan normatividades y demandas sociales ante los sujetos y su vida sexual. ${ }^{4}$

Como se ha mencionado, el reconocimiento de la sexualidad como parte integral de la salud y del desarrollo se consolidó en la Conferencia de El Cairo de 1994, resultado de un proceso de transformación de conceptos y programas en torno a la población. Como lo describe José Barzelatto ${ }^{5}$ este proceso ha ido desde los conceptos y programas de "control de la natalidad", pasando por la planificación familiar y derivando en las propuestas de salud reproductiva y salud sexual. En la primera conferencia de la onU sobre población, en Bucarest en 1974, los gobiernos consideraron, desde una perspectiva demográfica, que el control natal era una herramienta necesaria para el desarrollo de la sociedad y se empezaron a crear los programas de planificación familiar. Durante la segunda conferencia de población, en México, en 1984 los gobiernos no lograron ponerse de acuerdo en cuanto a la relación entre el desarrollo social, el desarrollo económico y el desarrollo demográfico. Fue en la tercera conferencia, llamada Conferencia Internacional de Población y Desarrollo, en El Cairo en 1994, en donde ya se consumó un cambio fundamental en los conceptos dando como resultado un nuevo estándar internacional: el de la salud sexual y reproductiva como solución a los problemas de población y desarrollo. Aunque, de acuerdo con Sonia Correa, ${ }^{6}$ el término "derechos reproductivos" es de origen reciente y se presume que fue originado con la fundación de la Red Nacional por los Derechos Reproductivos, en Estados Unidos en 1979, fue en la reunión de El Cairo donde se aceptó de manera consensuada que la sexualidad es un tema de derechos humanos y que los derechos reproductivos son elementales para lograr la salud sexual y reproductiva. Sin embargo, no fue en ese momento, sino hasta la Iv Conferencia Internacional de la Mujer en Beijing, en 1995, cuando se

${ }^{3}$ Véase Michel Foucault, Historia de la sexualidad, Tomo I, La voluntad de saber, Siglo xxı, México, 1987.

${ }^{4}$ Gayle Rubin, "Reflexionando sobre el sexo: notas para una teoría radical de la sexualidad", en Vance, Carole (Comp.), Placer y peligro, Roultdge \& Kegan Paul, Boston, 1984.

5 José Barzelatto, "Conferencia magistral Desde el control de la natalidad hacia la salud sexual y reproductiva: la evolución de un concepto a nivel internacional”, Memoria de la Reunión Nacional de Donatarios del Programa de Salud Reproductiva y Población de la Fundación Ford en México, Cuernavaca, Morelos, julio de 1995.

${ }^{6}$ Sonia Correa y Rosalind Petchesky, "Los derechos reproductivos y sexuales: Una perspectiva feminista", capítulo 8 de libro de G. Sen, A. Germain y L. Chen (Eds.), Population Policies, Reconsidered (Healdt,

Empowerment, and Rights), Harvard University Press, USA, 1994. 
reconoce la importancia de los derechos sexuales para el bienestar social. Como tema reconocido internacionalmente como parte de los derechos humanos, los derechos reproductivos y los derechos sexuales se han ido desarrollando en las discusiones internacionales sostenidas por los estados, impulsadas principalmente por la sociedad civil organizada en torno a los temas de mujeres y salud sexual y reproductiva.

Además de estas conferencias internacionales, hay otros eventos que son parte de los antecedentes conceptuales e históricos de los derechos reproductivos y los derechos sexuales que pueden situarse como un panorama básico de la aparición y el desarrollo de estos derechos en el ámbito internacional. Sobre esto, Violeta Bermúdez señala como hitos en el desarrollo del concepto de derechos sexuales y derechos reproductivos: a) la Conferencia sobre Derechos Humanos de Teherán, 1968, en la que se estableció por primera vez el derecho de las parejas para decidir el número de hijos y su espaciamiento; b) la Conferencia de Población de Bucarest, 1974, cuyo Plan de Acción Mundial de Población reconoció el papel del Estado en asegurar ese derecho, incluyendo la información y acceso a métodos de control de la natalidad; c) la Conferencia Mundial del Año Internacional de la Mujer, México (1975), en cuya Declaración se reconoció el derecho de la mujer a la integridad física y a decidir sobre el propio cuerpo, el derecho a la opción sexual y los derechos reproductivos, incluyendo la maternidad voluntaria; d) la Convención sobre la Eliminación de todas las formas de Discriminación contra la Mujer (1979), que fue el primer tratado internacional que aseguró la igualdad de acceso a los servicios de planificación familiar.

$\mathrm{Al}$ respecto, es importante resaltar que tanto la CIPD de El Cairo, y la IV сім en Beijing, fueron espacios amplios de reflexión e impacto mundial en torno a la concepción mundial sobre la salud, la sexualidad y la reproducción. Los acuerdos derivados de esas reuniones de los estados miembros de la onu han surgido en gran medida como el fruto de las demandas y propuestas de la sociedad civil organizada, especialmente de las vinculadas con los movimientos feministas, gay y homosexuales, democráticos, y de derechos humanos. Los espacios de trabajo para la elaboración de esos acuerdos, además de su difusión y aplicación, han sido financiados por diversos organismos internacionales interesados en promover y atender dichas demandas sociales. ${ }^{7}$

${ }^{7}$ Para ampliar esta visión, véase Clara Jusidman, "La experiencia de la participación de México en la Iv Conferencia Mundial de la Mujer, celebrada en Pekín”, en García, Brígida (Coord.) Mujer, género y 
En el Programa de Acción de la III CIPD de El Cairo, y la Plataforma de Acción de la rv сім se aborda el tema de la salud reproductiva y la salud sexual y los derechos sexuales y reproductivos, en el ámbito internacional. Se plasman acuerdos como prioridad para el desarrollo mundial, el logro de la salud reproductiva y el respecto de los derechos reproductivos. Específicamente, la CIPD fue un hito al llevar el debate demográfico sobre los programas de población hacia un concepto más complejo y amplio de salud sexual y reproductiva, incluyendo la planificación familiar y resaltando los intereses, las necesidades y los derechos de la mujer y de las y los jóvenes como elementos fundamentales del desarrollo. ${ }^{8}$ Por su parte, la IV cIM resaltó la necesidad de lograr la igualdad y el potenciamiento de las mujeres en todos los ámbitos de la vida. Así, la Plataforma de Acción de Beijing retoma los conceptos de salud reproductiva y sexual, y derechos reproductivos, pero los amplía a la discusión explícita de los derechos sexuales. En ella se reconocen como derechos humanos incluyendo el derecho a tomar decisiones libre y responsablemente, y sin coacción, discriminación, ni violencia, en todo lo relacionado con la vida sexual, la salud sexual y reproductiva.

Además de resaltar la necesidad de más y mejores servicios de salud reproductiva y sexual para mujeres, y la importancia de promover la equidad y la igualdad entre hombres y mujeres, estos dos documentos enfatizan en la importancia de atender las demandas de las grandes proporciones de jóvenes en el mundo, relacionadas con la salud, la educación y el empleo. El desafío y la responsabilidad de los estados, las familias y la comunidad internacional de atender a esta población quedaron plasmados en ellos. Al no contar con información y acceso a los servicios de calidad los y las adolescentes se evidenciaron en ese momento como la población blanco de los mayores problemas como resultado de una deficiente o total ausencia de salud reproductiva. Especialmente la cumbre de El Cairo puso el dedo en la llaga en cuanto a los pocos programas dirigidos para esta población en materia de salud reproductiva y educación sexual, así como en su baja calidad; y la conferencia de Beijing confırmó la urgente necesidad de atender estos problemas. De esta manera, ambos documentos defendieron los derechos de las y los adolescentes a la privacidad, a la confidencialidad, al respeto y al consentimiento informado, haciendo un llamado a

población en México, El Colegio de México/Sociedad Mexicana de Demografía, México, 1999, pp. 483-544.

${ }^{8}$ Véase Programa de Acción de El Cairo, 1994, párrafo 7.2. 
proveerles de los recursos educativos y de servicios necesarios, basándose en el marco de los instrumentos internacionales vinculatorios como la Convención sobre los Derechos del Niño y la Convención sobre la Eliminación de todas las formas de Discriminación contra la Mujer. Estos documentos internacionales firmados por el gobierno mexicano, sí representan fuertes compromisos morales que lo obligan públicamente a cumplir. Si bien la Convención sobre los Derechos del Niño y la Convención sobre la Eliminación de todas las formas de Discriminación contra la Mujer son instrumentos jurídicos con validez en nuestro país, al estar ratificados por el Congreso de la Unión, también han sido una herramienta fundamental para la búsqueda del cumplimiento de los compromisos de El Cairo y Beijing. De la misma manera, las jurisprudencias establecidas por los Comités de Vigilancia de ambas convenciones así como los del Pacto por los Derechos Civiles y Políticos y el Pacto por los Derechos Económicos, Sociales y Culturales, ${ }^{9}$ han contribuido a que países como México sean objeto de vigilancia y sustenten sus políticas públicas para el cumplimiento de los derechos reproductivos y sexuales con base en esas herramientas jurídicas. En el ámbito internacional se ha reconocido la importancia de ese marco jurídico internacional para el diseño, planeación, desarrollo y evaluación de políticas públicas abocadas a brindar condiciones para el ejercicio de los derechos sexuales y reproductivos. ${ }^{10}$

Como parte del desarrollo y atención de esas demandas sociales, algunos organismos civiles internacionales se han dado a la tarea de establecer algunos catálogos mínimos de lo que son los derechos sexuales y reproductivos. Es así que en 1995 la Federación Internacional de Planificación de la Familia elabora y aprueba una Carta de los Derechos Sexuales y Reproductivos. ${ }^{11}$ Esta carta es una base del trabajo de las organizaciones de planificación familiar asociadas a la IPPF en más de 120 países del mundo. Asimismo, fue utilizada como base de la Campaña de las Naciones Unidas por los Derechos de las Mujeres, impulsada por la onU en 1998. Por otra parte, está el catálogo de Derechos Sexuales y Reproductivos de la Organización Mundial de la Salud (oms), que hace mayores especificacio-

\footnotetext{
${ }_{9}^{9}$ Véase Alicia Elena Pérez Duarte, "Una lectura de los derechos sexuales y reproductivos desde la perspectiva de género. Panorama internacional entre 1994 y 2001”, en Revista Jurídica Boletín de Derecho Comparado, Instituto Nacional de Ciencias Jurídicas, unAm. No. 105, septiembre-diciembre de 2002.

${ }^{10}$ Véase "Advocaci: advocacia cidadâ pelos directos humanos”, Derechos sexuales y derechos reproductivos em la perspectiva de los derechos humanos, UNFPA, Río de Janeiro, 2003.

11 Para más información, consulte Carta de IPPF de derechos sexuales y reproductivos, Federación Internacional de Planificación de la Familia, Londres, 1996.
} 
nes en relación con la vida sexual, aunque no podemos decir que incluye todo lo referente a ella. La idea de la oms es establecer la importancia del ejercicio libre y respetuoso de la dignidad de las personas a través del respeto a estos derechos para garantizar la convivencia y la armonía sexual entre hombres y mujeres, entre adultos y menores. Por último, podemos mencionar que la Asociación Mundial de Sexología elaboró y publicó una Declaración de Derechos Sexuales en Valencia, España, en 1997. Esta declaración parte de la idea de que la sexualidad es una condición integral de la personalidad de todo ser humano, y su desarrollo es esencial para el bienestar individual, interpersonal y social. En ella se reconoce que la sexualidad se construye a través de la interacción entre el individuo y las estructuras sociales, además de que se vincula con la salud, estableciendo a la salud sexual como un derecho humano fundamental.

El eje de articulación de este tipo de documentos declarativos es precisamente la consideración de la sexualidad como campo de derechos humanos, donde se establece la protección de la salud sexual y reproductiva como parte de los derechos humanos, aun y cuando sean temáticas que motiven fuertes controversias por colocar en el centro del debate social y político elementos de la vida y las relaciones humanas poco reconocidos hasta hace unas décadas, como son las desigualdades sociales de género, de clase, de etnia y de generación, el poder ejercido por las ciencias médicas, la sexualidad como fuente de placer y no necesariamente de procreación, y la consecuente diversidad sexual en tanto deseos y prácticas así como el reconocimiento del derecho a decidir sobre la maternidad o la interrupción del embarazo.

En la actualidad, la adolescencia y juventud, como etapa de vida construida históricamente, puede ser ubicada como un momento fundamental en la creación de nuevas opciones de convivencia. Las y los jóvenes, incluyendo adolescentes, por su proceso vital y por el estado actual de sociedades como la mexicana, también están buscando y construyendo estrategias posibilitadoras de mejores condiciones de vida. Uno de los aspectos que influyen en esa búsqueda podría ser el ejercicio de su sexualidad y sus posibles consecuencias, como un embarazo no previsto ${ }^{12}$ o el contagio de una infección de transmisión sexual, riesgos existentes en mayor grado

${ }^{12}$ Defna Feinholz define al embarazo no previsto como "toda concepción que resulta de una relación sexual que no la tenía contemplada como su objetivo" $(1999,113)$. Véase Feinholz, D., et al., "El dilema del embarazo no previsto: visión personal de salud", en revista Perinatología y Reproducción Humana, Instituto Nacional de Perinatología, Vol. 13, Número 1, 112-124, enero-marzo, 1999. 
cuando la práctica de relaciones sexuales está negada y/o rechazada y/o no prevista, y cuando no cuentan con las condiciones para ejercer su derecho a decidir sobre su cuerpo y su vida sexual.

\section{Derechos Sexuales de LAS Y LoS Jóvenes EN EL CONTEXTO JURÍDICO MEXICANO}

Los avances logrados hasta ahora en materia de derechos sexuales de las y los jóvenes en México son resultados del trabajo de las organizaciones civiles, así como de la voluntad del Estado mexicano, que han avanzado en la creación de programas para la generación de condiciones que posibiliten el ejercicio de estos derechos y el logro de una mayor salud reproductiva y sexual de la población en general, y de las y los jóvenes en particular. Además de los acuerdos comprometidos en El Cairo y Beijing, el gobierno mexicano se ha comprometido con los acuerdos de la Sesión Especial de las Naciones Unidas sobre VIH/SIDA, celebrada en junio de 2001. De esa sesión surgió la Declaración de Compromiso en la lucha contra el viH/SIDA "Crisis mundial-acción mundial", en la que se establece claramente la importancia del trabajo de y por las y los jóvenes para prevenir el síndrome y luchar contra él, lo que implica una ardua labor en materia de derechos sexuales para este sector de la población, incluyendo la información y educación sexual integral. Los derechos sexuales de las y los jóvenes en nuestro país han tenido aristas diversas de trabajo para su discusión, definición y difusión. Sin embargo, podemos identificar como un hito en esta cuestión, el Foro Nacional de Jóvenes por los Derechos Sexuales realizado en el año 2000. En él participaron jóvenes, especialistas y representantes de organizaciones gubernamentales y no gubernamentales con el fin de aprovechar ese espacio para reflexionar sobre los derechos sexuales de las y los jóvenes, sus definiciones y retos para desarrollarlos e integrarlos a las políticas públicas. Fue organizada por el Instituto Mexicano de la Juventud y la Dirección de Programas para la Juventud del Gobierno del Distrito Federal en colaboración con organizaciones civiles. Resultado de esa reunión fue la elaboración de la Declaración de los Derechos Sexuales de las y los Jóvenes Tlaxcala 2000, misma que abordó temas de información y educación, ejercicio y disfrute de la sexualidad, salud y servicios.

Como datos relevantes cabe destacar que con respecto a la educación sexual declararon su derecho a tener una educación sexual integral, objetiva, científica, temprana, laica y liberadora, que aborde el placer, la 
reproducción, la vida afectiva y el género en todas sus dimensiones, que sea incluyente y fomente la equidad de género y que promueva la toma de decisiones responsables y libres, impartida por personas respetuosas y capacitadas. En cuanto al ejercicio y disfrute de la sexualidad se destaca la declaración de que tienen derecho a no ser discriminados por razón alguna, a la autonomía sobre su cuerpo, la equidad, la privacidad sexual y la integrad corporal, y a vivir el erotismo y la sexualidad con quien lo decidan y sin que necesariamente sea con fines reproductivos, así como que se reconozca legalmente cualquier forma de unión entre personas jóvenes de cualquier sexo que tenga el fin de compartir la vida, los afectos y el erotismo. Con respecto a la sexualidad y los servicios, declararon tener derecho a servicios integrales, oportunos, eficientes, confidenciales y de calidad, sin discriminación por edad o sexo o cualquier otra condición; a recibir trato humano y digno por parte del personal, que a su vez, debe estar capacitado y actualizado; a conocer todo lo relacionado con métodos anticonceptivos y opciones para la prevención de infecciones de transmisión sexual, VIH, embarazos no planeados, además de que se les asegure el consentimiento libre e informado, acceder a servicios de calidad para la interrupción de embarazos no planeados ni deseados, y recibir orientación, atención y tratamientos integrales en caso de VIH/SIDA, ITS, violencia de género.

Como se puede ver, esta declaración recoge las preocupaciones de las y los jóvenes por su sexualidad y sus derechos incorporando los temas de las declaraciones internacionales que se han señalado en este artículo. Como en cada proceso histórico de definición y defensa de derechos humanos, esta Declaración de Tlaxcala 2000 ha sido el antecedente inmediato para la propuesta de un listado de derechos sexuales y reproductivos. Al recordar la Declaración Universal de los Derechos Humanos se evidencia que fue elaborada previamente a la elaboración de marcos jurídicos pertinentes para su promoción y defensa que actualmente se siguen desarollando y especificando cada vez más. De la misma manera esta Declaración de Tlaxcala 2000 vino a ser el documento a partir del cual se dio mayor impulso a la ubicación de los derechos sexuales de las y los jóvenes en los marcos legales vigentes de México. Uno de los resultados más relevantes de estos esfuerzos fue la publicación de la Campaña nacional por los derechos sexuales de las y los jóvenes: hagamos un hecho nuestros derechos”, la cual incluyó la publicación y distribución de la Cartilla de los Derechos Sexuales de las y los Jóvenes, y de pósters alusivos a esta temática por 
parte de la Comisión Nacional de los Derechos Humanos y organizaciones civiles que trabajan en la promoción y defensa de estos derechos, en el mes de enero de 2003.

La concreción de este tipo de declaraciones y campañas forma parte de los cambios en el contexto jurídico mexicano en torno a los derechos sexuales de las y los jóvenes. En especial, el fundamento jurídico básico es la Constitución Política de los Estados Unidos Mexicanos ${ }^{13}$ en su Título I, Capítulo I, llamado también "De las garantías individuales". El artículo 1 da sustento como marco general para el derecho de las y los jóvenes a disfrutar de las garantías otorgadas por la Constitución, así como para el derecho a no ser discriminado por origen étnico o nacional, el género, la edad, las capacidades diferentes, la condición social, las condiciones de salud, la religión, las opiniones, las preferencias, el estado civil o cualquier otra causa o motivo.

Como fundamento del derecho a la manifestación pública de los afectos y a vivir libre de toda discriminación, también se cuenta con el artículo $2^{\circ}$ constitucional, aunque se centra particularmente para el caso de las poblaciones indígenas. Respecto al derecho a ejercer y disfrutar de la vida sexual, a la información y educación científica y laica sobre sexualidad, se encuentra el respaldo en el artículo $3^{\circ}$ que establece el derecho a la educación.

El artículo $4^{\circ}$ constitucional versa fundamentalmente sobre la igualdad de la mujer y el hombre ante la ley, la organización y desarrollo de la familia, el derecho a decidir de manera libre, responsable e informada sobre el número y el espaciamiento de sus hijos; la protección de la salud; la satisfacción de necesidades de las y los niños en cuanto a la alimentación, salud, educación y sano esparcimiento para el desarrollo integral, así como el respeto a la dignidad de la niñez y al pleno ejercicio de sus derechos. De esta manera, ha sido un amplio marco de fundamento constitucional para el derecho a decidir de forma libre sobre el cuerpo y la sexualidad, a disfrutar de la vida sexual, a la manifestación pública de los afectos, a la decisión sobre con quién compartir la vida y la sexualidad, a vivir libre de violencia sexual y de toda discriminación, a la libertad reproductiva y la igualdad de oportunidades y la equidad, así como el derecho a la información y educación sexual completa, científica y laica, y a los servicios oportunos y de calidad de salud sexual y salud reproductiva. Es con base en este artículo con que se ha avanzado en México, la integración

${ }^{13}$ La Constitución Política mexicana vigente se puede consultar en www.cndh.org.mx/Principal/document/juridica/constitu/constitu.htm 
de elementos de educación sexual integral a la política de la educación pública en los niveles básicos, específicamente la currícula del $5^{\circ}$ y $6^{\circ}$ grado de primaria, y a la asignatura de "Formación cívica y ética del nivel secundaria. Además, el artículo $6^{\circ}$ constitucional versa el tema de la libre manifestación de las ideas y el derecho a la información, por lo que también ha sido sustento jurídico para los derechos mencionados y el derecho a la participación en la elaboración, planeación, desarrollo y evaluación de las políticas públicas sobre sexualidad en tanto dicho proceso deviene un espacio de manifestación de ideas y propuestas por parte de las y los jóvenes, en tanto también está sustentado en el artículo $8^{\circ}$ constitucional que aborda el derecho de petición de los ciudadanos del país, y el $9^{\circ}$ que establece el derecho de asociación.

A su vez, el mismo artículo 9 y el 16 sustentan el derecho a la intimidad y la vida privada, a la manifestación pública de los afectos, así como a la libertad reproductiva la cual involucra el consentimiento informado por parte de las y los jóvenes que acuden a los servicios de salud sexual. Por su parte el artículo 20, que prohíbe la tortura, intimidación e incomunicación, el 21 que establece la seguridad pública como una función a cargo de la federación y todos los niveles de gobierno, y el 22 que prohíbe penas de mutilación, infamia o tormento de cualquier especie, se ubican como un fundamento del derecho a vivir libre de violencia sexual. Finalmente, el artículo 24 establece la libertad de profesar la creencia religiosa, lo cual también sirve como sustento del derecho a decidir de forma libre sobre el propio cuerpo y la sexualidad, el derecho a la información y la educación sexual, de acuerdo con dicha libertad y las creencias de cada joven.

A partir de estos artículos constitucionales se han desarrollado algunas leyes que respaldan algunos de los derechos sexuales de las y los jóvenes, como es el caso de la Ley Federal de Protección de los Derechos de los Niños, Niñas y Adolescentes (LPDNNA), que sustenta información y métodos anticonceptivos para adolescentes, y en el mismo sentido, algunas leyes estatales que siguen la misma propuesta de esta ley federal.

En este contexto, es importante recordar que para algunos derechos sexuales de las y los jóvenes, como son el de decidir con quién compartir su vida y su sexualidad, el derecho a la libertad reproductiva y a servicios de salud sexual y salud reproductiva, algunas leyes estatales, principalmente códigos civiles y leyes en materia de salud establecen algunas limitaciones para los menores de edad. La alineación de las leyes estatales con las federales y con los pactos y convenciones signados y ratificados por 
el gobierno mexicano todavía tiene algunos rezagos y retos por superar, especialmente cuando se trata de adolescentes, quienes al ser menores de 18 años, siguen enfrentando la situación de depender de los criterios de sus padres o tutores para el acceso al ejercicio pleno de estos derechos.

En México uno de los aspectos en donde más se ha fortalecido el marco legal de los derechos sexuales de las y los jóvenes es en el ámbito de la anticoncepción y de los servicios de salud sexual para ese sector de la población. Específicamente, el ejemplo ha sido la normatividad federal en salud que incorporó en la Nom-005-SSA2-1993 el año 2003 la píldora de anticoncepción de emergencia en el marco de la obligación de los servicios de salud de brindar métodos de anticoncepción a las y los adolescentes que así lo requieran. Esta norma sustenta el derecho de todas las personas, incluyendo las y los adolescentes, a pedir y recibir información y educación, consejería, servicios y métodos anticonceptivos que requieran de parte del personal de salud. Y define para cada método que: "están indicados para mujeres en edad fértil con vida sexual activa, nuligestas, nulíparas, o multíparas, incluyendo adolescentes". Así, establece que los servicios de planificación familiar en todo lo que incluye en términos de difusión, información, educación, consejería, selección, prescripción y aplicación de todos los métodos anticonceptivos deben "ofrecerse, independientemente de la causa que motive la consulta o demanda de estos servicios, a todas las personas en edad reproductiva, incluyendo a las y los adolescentes". Y enfatizando la importancia de la consejería y el respeto al derecho del consentimiento informado, define que todos los métodos anticonceptivos, incluida la anticoncepción de emergencia, son recomendados para las y los adolescentes.

Entre los beneficios de promover y brindar la anticoncepción a las y los adolescentes ${ }^{14}$ se reconoce que se promueve las relaciones sexuales placenteras, seguras y responsables, se previenen embarazos no planeados y la práctica de abortos inseguros, así como se facilita el logro de mejores niveles de calidad de vida para las y los adolescentes en tanto pueden realizar sus proyectos de estudios y actividades de desarrollo y esparcimiento personal y social, posponiendo la reproducción para el momento en que estén preparados emocional, social y económicamente. Además, se fomenta la participación responsable del hombre al involucrarlo en las decisiones sobre la anticoncepción; la mayor dedicación a la crianza de las y los hijos

${ }^{14}$ Véase D. Billings, F. Rosas y N. Gasman, En México, sí se pueden ofrecer servicios de anticoncepción a adolescentes. Normatividad nacional e internacional, lpas de México, 2004. 
cuando éstos son deseados y planeados, y la consecuente reducción de la mortalidad materna en adolescentes y la mortalidad infantil.

La legislación de la ciudad de México también ha integrado cambios sustanciales que posibilitan la interrupción legal del embarazo antes de las doce semanas de gestación, brindando la posibilidad efectiva de que se realice en caso de que así lo decida la mujer en edad reproductiva. El 24 de abril del presente año, la Asamblea Legislativa aprobó el dictamen que despenaliza al aborto en las primeras doce semanas de gestación y obliga al gobierno de la ciudad a otorgar servicios de consejería médica y social gratuita en materia de atención a la salud sexual y reproductiva. ${ }^{15}$ Se trató de reformas al Código Penal del Distrito Federal y la ley de salud de esta ciudad, lo que dio paso a la posibilidad de que las mujeres jóvenes que se embarazaran por violación o por alguna causa diferente a la decisión y el deseo reconocido de embarazarse, puedan acceder a la interrupción legal del embarazo antes de la semana 12 de gestación. El ejercicio del derecho a la información y a servicios de salud sexual y reproductiva seguros también se vio fortalecido con estas reformas en esta capital.

Como se puede observar, en general el sustento legal de estos servicios para las y los jóvenes se puede ubicar en la Constitución Política mexicana y las diferentes leyes federales como la Ley Federal de Salud, Ley General de Población, Ley Federal para la Protección de los Derechos de Niñas, Niños y Adolescentes, y la Ley Federal para Prevenir y Eliminar la Discriminación, así como en las respectivas leyes estatales en gran parte de las entidades federativas. Sin embargo, no todos los estados han integrado estos derechos en sus marcos legales y todavía es muy deficiente la reglamentación de procedimientos jurídicos y de servicios de salud para hacerlos efectivos.

\section{Educación SEXUAL INTEgRaL:}

aVANCES DEL DERECHO SEXUAL de LAS Y LOS JóveneS EN MÉXICO

Los debates sobre la pertinencia de la educación sexual involucran las concepciones y valoraciones referentes a la sexualidad. Para comprender el desarrollo de la educación sexual integral como un derecho de las y los jóvenes mexicanos es importante aclarar por qué es necesaria la educación sexual integral.

${ }^{15}$ Véase La Jornada, 25 de abril de 2007, Nota periodística de Gabriela Romero y Raúl Llanos, Sección: Capital. 
En México existen problemas de salud pública que requieren ser atendidos con estrategias que incluyan una educación sexual integral. Específicamente, la población joven es considerada como un sector vulnerable ante la presencia de enfermedades como el viH/SIDA y las infecciones de transmisión sexual. De acuerdo con el Centro Nacional para la Prevención y el Control del viH/SIDA (CENSIDA) las y los jóvenes a partir de 15 años son la población más vulnerada por el viH en México. ${ }^{16}$ La Secretaría de Salud estima que en el país hay alrededor de 92,000 personas infectadas con el virus de inmunodeficiencia humana, de las cuales se sabe que el $91 \%$ se contagió por la vía sexual. ${ }^{17}$

Los datos del Programa de Acción: VIH/SIDA e Infecciones de Transmisión Sexual (ITS) (SSA, 2002) señalan que alrededor de 50 millones de casos nuevos de iтs ocurren anualmente en América Latina, de los cuales más de la mitad ocurren entre adolescentes y adultos jóvenes entre los 15 y 24 años de edad (sSA, 2002, 15). Según este programa de la Secretaría de Salud, en México la epidemia del SIDA se ha ampliado principalmente a través de la vía del contagio sexual. Las altas tasas de rTs y de embarazos no planeados de jóvenes muestran que las relaciones sexuales sin protección tienen un alto riesgo. "La iniciación temprana de sus relaciones sexuales representa un factor de riesgo adicional, ya que la tasa de cambio de pareja sexual es más elevada entre los jóvenes de 15 a 24 años" (ssA, 2002, 17). Asimismo, este programa gubernamental frente al VIH/SIDA establece a la población juvenil, y en particular a las mujeres y a los hombres que tienen sexo con otros hombres, como los sectores más vulnerables para el contagio de esta enfermedad.

Por otra parte, aun y cuando se han desarrollado visiones críticas, desde las ciencias sociales, con respecto a la definición del embarazo en la adolescencia y la juventud, ${ }^{18}$ hoy en día se sabe que en México se presentan 355,000 embarazos en mujeres adolescentes, de las cuales alrededor de 9,500 son adolescentes entre los doce y los 18 años, que están en riesgo de abandonar la primaria o la secundaria por estar embarazadas o ya ser ma-

\footnotetext{
${ }^{16}$ Véase Agencia Notiese, 4 de agosto de 2005, Nota periodística de Rocío Sánchez.

${ }^{17}$ Véase El Universal (18 de mayo de 2005), Sección: México, pág. 19.

${ }^{18}$ Véase por ejemplo a Rosario Román Pérez Del primer vals al primer bebé. SEP-Instituto Mexicano de la Juventud, México, 2000; Claudio Stern y Elizabeth García, "Hacia un nuevo enfoque en el campo del embarazo adolescente", en Stern, Claudio y Figueroa, J. Guillermo (Coords.), Sexualidad y salud reproductiva. Avances y retos para la investigación, El Colegio de México, México, 2001, pp. 331358; Claudio Stern, "Embarazo adolescente", en Demos. Carta demográfica sobre México, No. 8., 1995, pp. 11-12.
} 
dres jóvenes, de acuerdo con la Secretaría de Educación Pública (SEP). ${ }^{19}$ De alguna manera, la prevención de este tipo de embarazos, que en la mayoría de los casos son no previstos y muchos de ellos no deseados, forma parte de los fines con que se han planteado diferentes programas de educación sexual en este país.

La educación sexual planeada y organizada debe basarse en datos verídicos y confiables que describan la realidad de la vida sexual de las y los jóvenes. En México se han realizado algunos estudios cuantitativos confiables que han dado cuenta de algunos aspectos relevantes sobre la vida sexual de las y los jóvenes, como por ejemplo, la edad de inicio de las relaciones sexuales, el conocimiento de anticonceptivos, las prácticas sexuales más frecuentes, entre otros. ${ }^{20}$

Entre los más recientes se encuentran las Encuestas Nacionales de Juventud 2000 (ENJ-2000) y 2005 (ENJ-2005). Sus resultados en los temas relacionados con la vida sexual de las y los jóvenes brindan datos relevantes a considerar a la hora de formular programas e intervenciones, así como de sustentar propuestas de ley y regulación jurídica para el avance de las condiciones de posibilidad para el ejercicio de sus derechos sexuales.

Por ejemplo, en relación al noviazgo la encuesta de 2000 refleja que es una situación valorada como importante. El 85\% de los y las encuestadas reportó haber tenido al menos un noviazgo. La edad en que se produce el primer noviazgo generalmente es antes de los 20 años, especialmente en el rango de edad de 15 a 19 años. Respecto a las conductas que se permiten en el noviazgo, un poco menos de la mitad respondió que sólo besos y abrazos, seguidos de los que afirmaron permitir cualquier tipo de caricia con excepción de las relaciones sexuales, las cuales sólo fueron reportadas como permitidas por el 11\%. Ocho de cada diez jóvenes afirmaron haber estado enamorados alguna vez en su vida, lo que sugiere la importancia que alcanzan a tener las relaciones sentimentales de pareja en la juventud mexicana.

Respecto al conocimiento de métodos anticonceptivos y los de protección contra infecciones de transmisión sexual, en ambas encuestas la mayoría de los encuestados respondió conocerlos.

En la encuesta del 2000 el 55\% de los encuestados reportó haber tenido relaciones sexuales, mientras que en la encuesta del 2005 fue el $48 \%$,

${ }^{19}$ Véase el periódico El Universal (25 de mayo de 2005), Sección: México, p. 16.

${ }^{20}$ Ejemplo de ello fue la Encuesta Nacional sobre Sexualidad y Familia en Jóvenes de Educación Media

Superior, realizada por el Consejo Nacional de Población en 1988. 
confirmando la aceptación de haberlas tenido en la mitad de la población joven. La edad de inicio está fundamentalmente en el rango de entre 15 y 19 años para las mujeres y entre 12 y 14 años para los hombres, según los resultados de 2005.

Tanto hombres como mujeres reportan que su primera relación sexual fue en su mayoría con su novio/a, lo que sugiere la importancia de las relaciones amorosas en el inicio de la práctica sexual en pareja. Además, en el caso de las mujeres, reportaron en segundo lugar al esposo y por último a un amigo, mientras que en los hombres en segundo lugar se ubicó a una amiga y en un rango inferior a una sexoservidora.

La encuesta del 2000 cuestionó la frecuencia con que han tenido relaciones en los últimos tres meses, dando como resultado que seis de cada diez jóvenes respondió que lo hacen entre una y tres veces por semana. Es interesante que más mujeres (46\%) que hombres (36\%) reportó tener relaciones sexuales de una a tres veces por semana; y por otro lado, más hombres (26\%) que mujeres (19\%) reportó no haberlas tenido en los últimos tres meses. Ciertamente estos datos reflejan la necesidad de profundizar más en el conocimiento de la frecuencia en las relaciones sexuales por parte de las mujeres y los hombres jóvenes, pero también de elementos que intervienen para asumirlo, declararlo, realizarlo, y sus condiciones, identificando particularidades de género que pueden estar interviniendo en el ejercicio de su sexualidad y las elecciones para ejercer sus derechos en términos de la autodeterminación y la prevención de consecuencias no deseadas, por ejemplo.

En cuanto al conocimiento de métodos anticonceptivos, la encuesta de 2005 reflejó que 9 de cada 10 jóvenes dicen conocer algún método, siendo el condón el más mencionado, seguido de las píldoras. En el caso de los hombres, en tercer lugar mencionaron a los métodos definitivos como las ligaduras de trompas y la vasectomía, mientras que las mujeres mencionaron al dispositivo intrauterino seguido por los inyectables, lo que sugiere que ellas tienen más información sobre métodos no definitivos para evitar el embarazo.

También es relevante que más del $60 \%$ de los encuestados declararon utilizar algún método anticonceptivo, dato que sugiere que la brecha entre contar con información y usarlos se ha reducido de manera importante.

Por otra parte, en relación con el tema de las infecciones de transmisión sexual, 8 de cada 10 jóvenes, tanto hombres como mujeres, declararon conocer cuáles son, además de que las dos formas para prevenir una in- 
fección es el uso del condón y en pocos casos (16\%) se reportó no tener relaciones sexuales.

Como se puede ver, estos datos muestran que tanto los hombres como las mujeres jóvenes que inician una vida sexual en pareja tienen encuentros sexuales de manera frecuente y requieren de información y medidas de prevención de consecuencias no deseadas, y más allá, necesitan, desde su lugar de sujetos de derechos sexuales y reproductivos, condiciones que les posibiliten el ejercicio de tales derechos en beneficio de su vida presente y futura.

Respecto a las fuentes de información, sólo la encuesta de 2000 contiene información referente a que el 33\% de los hombres declaró haber aprendido de sexualidad en la escuela, el 22\% de los padres y el 21\% por sí mismos. Las mujeres declararon que el 34\% aprendió de sexualidad en la escuela, el $27 \%$ de los padres y el $18 \%$ por sí mismas. El $70 \%$ del total de jóvenes encuestados afirmó que confía más en los médicos, el 65\% en los maestros y el 58\% en los sacerdotes. Así, de acuerdo con estos datos, la escuela sigue siendo el lugar más común en el que las y los jóvenes reciben información con respecto a su sexualidad.

Con estos resultados se observa que en ambas encuestas se encuentran evidencias de que más de la mitad de la población juvenil declara en este tipo de estudios estar teniendo relaciones sexuales; una vida sexual activa en la que las relaciones sentimentales son muy importantes e influyen en sus prácticas y comportamientos. La edad de inicio de vida sexual coital sigue siendo baja, lo cual apunta a la necesidad de reconocerlo de manera diferenciada para hombres y mujeres, y de brindarles información y herramientas útiles que les permitan decidir de manera responsable e informada sobre su cuerpo y sus prácticas sexuales, como parte del ejercicio de sus derechos. La valoración que hacen de su primera relación sexual y de su vida sexual en general es tan positiva que también justifica la necesidad de aceptarlo y de proveerles de actividades y materiales que les permitan reflexionar sus decisiones, sus prácticas, así como la conveniencia de tomar decisiones responsables y comprometidas con su autocuidado y su protección para prevenir consecuencias no deseadas, como pueden ser psicológicas, como sentimientos de culpa, o consecuencias en su salud y su vida como puede ser el adquirir una infección de transmisión sexual o tener un embarazo no previsto para su edad y sus condiciones de vida.

Además de encuestas como la ENJ-2000, hoy en día hay múltiples estudios cualitativos hechos en distintos países y en México, que muestran que 
la experiencia sexual en adolescentes y jóvenes es amplia y variada y que no se puede negar, por lo que es mejor reconocerla y enfrentar la necesidad que tiene la juventud de contar con información, educación y desarrollo de habilidades para vivir su sexualidad con plena responsabilidad. ${ }^{21}$

Lo anterior permite afirmar la relevancia de la educación sexual integral en tanto se reconoce la práctica sexual de las y los jóvenes. Las condiciones para que accedan a esta educación es parte de lo que se necesita para que ejerzan su derecho a estar informados, recibir educación con elementos científicos, veraces y laicos, y decidir de manera libre, informada y responsable cómo quieren vivir su sexualidad. En este sentido cabe comentar que los programas de educación sexual que sólo promueven la abstinencia resultan ser incompletos para el amplio abanico de prácticas y elecciones que toman las y los jóvenes en cuanto a su vida sexual.

De acuerdo con estudios e investigaciones científicas recientes, los programas de educación sexual que promueven sólo abstinencia, no han demostrado disminuir las prácticas sexuales de las y los jóvenes, y mucho menos, la ocurrencia de embarazos no previstos o de infecciones de transmisión sexual. El Center for Aids Prevention Studies (CAPS) afirma que no es suficiente enseñarles a los jóvenes que deben decir "no" a las prácticas sexuales. ${ }^{22}$ "Una educación sexual completa comienza con la abstinencia, pero además toma en cuenta que muchos jóvenes van a decidir tener sexo, por lo tanto tienen que saber las consecuencias y la manera de protegerse a sí mismos. Estos programas incluyen la instrucción sobre el comportamiento sexual seguro, incluyendo el uso del condón y de otros anticonceptivos." ${ }^{23}$ Los datos de las encuestas nacionales y los estudios cualitativos

\footnotetext{
${ }^{21}$ Véase por ejemplo Peter Aggleton, "Sexual practices, sexually transmited diseases and AIDS amongst young people”, Seminario Internacional sobre Avances en Salud Reproductiva y Sexualidad, El Colegio de México, noviembre del 18 al 21, de 1996; Lucille Atkin, Noemí Ehrenfeld y Susan Pick, "Sexualidad y fecundidad adolescente", en Ana Langer y Kathryn Tolbert (Edits.), Mujer: sexualidad y salud reproductiva en México, The Population Council, 1996; Xochitl Castañeda, Raquel Castañeda, Emperatriz Delgado, Nora Brie, Elizabeht Cancino y Martín de la Cruz, "Adolescencia, género y sida en áreas rurales de Chiapas”, en Esperanza Tuñón (Coord.) Género y salud en el sureste de México, El Colegio de la Frontera Sur-Universidad Juárez Autónoma de Tabasco, México, s/f, pp. 55-86; Yuriria Rodríguez y Gabriel Contreras, Monografía de la clase media alta en la colonia San Jerónimo Lídice, Mecanograma, Proyecto de investigación: Significados e implicaciones del embarazo adolescente en distintos contextos socioculturales de la República Mexicana, Investigación auspiciada por el Consejo Nacional de Ciencia y Tecnología y El Colegio de México, 1998; Gabriela Rodríguez, "Sexualidad juvenil", en Pérez lslas, José A. (Comp.), Jóvenes: una evaluación del conocimiento. La investigación sobre juventud en México 1986-1999, 2a edición corregida y aumentada, Secretaría de Educación Pública-Centro de Investigación y Estudios sobre Juventud del Instituto Mexicano de la Juventud, México, 2000.

${ }^{22}$ Center for Aids Prevention Studies (CAPS), Hoja Informativa 30S, abril de 1998, Preparada por Chris Collins y Jeff Stryker, traducida por Romy Benard-Rodríguez.

${ }^{23}$ Idem.
} 
realizados en México en relación con la sexualidad de las y los jóvenes son contundentes al mostrar que efectivamente muchos de ellos y ellas están decidiendo tener una vida sexual activa, de manera que requieren de instrucción sobre el uso del condón y de anticonceptivos, para tener una práctica sexual segura y libre de violencia y consecuencias no deseadas.

Incluso cabe retomar datos de estudios donde se han reportado los procesos implementados en programas de educación sexual que sólo promueven la abstinencia y no brindan información confiable de métodos anticonceptivos y preventivos de infecciones de transmisión sexual, como es el caso del informe de Human Rights Watch, The Less They Know, the Better: Abstinence-Only HIV/AIDS Programs in Uganda,$^{24}$ donde se informa que los programas de sólo abstinencia en ese país han retirado la información amplia y crítica sobre el vIH/SIDA, incluida la información sobre condones, sexo más seguro y los riesgos de contraer el viн en el matrimonio. Además, los materiales educativos para jóvenes de nivel de escolaridad de secundaria, incluyen información falsa respecto a que los condones de látex tienen poros microscópicos por los que puede filtrarse el viн, y que el sexo prematrimonial es una forma de "desviación". ${ }^{25}$ Según Jonathan Cohen, lo anterior contribuye a una disminución en la información que reciben niños y jóvenes respecto a cómo prevenir el VIH/SIDA, dejando a la población infantil y juvenil de ese país en mayor riesgo de contraer el $\mathrm{VIH}^{26}$

Por su parte, Kirby reporta que se han publicado seis estudios en revistas evaluadas por expertos en la materia, en los cuales se realizó un examen a la efectividad de los programas de sólo abstinencia. ${ }^{27}$ Según él, ningún programa de los evaluados demostró ser efectivo y eficaz para el logro de la prevención de embarazos en la adolescencia y juventud. Asimismo, en su evaluación de los programas de educación sexual que sí fueron eficaces, Kirby resalta aquellos que fueron diseñados de acuerdo con la edad y la experiencia de la población joven, con un enfoque en el comportamiento sexual de riesgo, con bases teóricas bien fundamentadas, con información sobre cómo evitar tener sexo sin protección, así como con prácticas de

${ }^{24}$ Traducción: Cuanto menos sepan mejor: los programas de sólo abstinencia contra el VIH/SIDA en Uganda.

${ }^{25}$ Human Rigths Watch, Noticias: Uganda, Los "programas de sólo abstinencia" se apropian del éxito de la lucha contra el SIDA. Véase en www.hrw.org [recuperado el 8 de agosto de 2005].

${ }^{26}$ Jonathan Cohen, investigador del Programa de vIH/SIDA de Human Rights Watch y uno de los autores del informe, en Idem.

${ }^{27}$ Véase D. Kirby, No Easy Answers: Research Findings on Programs to Reduce Teen Pregnancy, National Campaign to Prevent Teen Pregnancy, Washington, Dc, 1997. 
comunicación, negociación y formas de decir "no" cuando así lo decidan. Los estudios que han evaluado este tipo de programas de educación sexual integral demuestran su eficacia, en tanto han podido lograr el retraso del inicio de las relaciones sexuales, una disminución en la cantidad de parejas, y un aumento en el uso de anticonceptivos. ${ }^{28}$

Otro estudio que ha mostrado la ineficacia de los programas de sólo abstinencia es el realizado por investigadores de la Texas A\&tM University. ${ }^{29}$ Para el Dr. Buzz Pruit, aun y cuando los adolescentes de 29 escuelas de nivel bachillerato han recibido cursos de educación sexual de sólo abstinencia, su actividad sexual no ha disminuido, y por el contrario, ha ido en aumento. Desde el gobierno de George Bush como gobernador del estado de Texas, se ha dado una fuerte inversión en programas de educación sexual de sólo abstinencia hasta el matrimonio. Sin embargo, hay datos preocupantes respecto a la falta de eficacia de este tipo de programas, como el hecho de que en Texas alrededor de 200 adolescentes de entre 15 y 19 años de edad se embarazan diariamente, siendo uno de los estados junto con Nevada, California, Arizona y Florida, con una alta taza de embarazo adolescente. Asimismo, Texas es uno de los estados con altos números de casos de infecciones de transmisión sexual, como la gonorrea y la clamidia y el VIH/SIDA. ${ }^{30}$ El estudio de la Texas A\&tM University demuestra que hablar solamente de la abstinencia y no de las otras alternativas útiles para prevenir un embarazo o el contagio del VIH/SIDA, no logra los objetivos de evitar que las y los jóvenes tengan prácticas sexuales vaginales, orales y anales, así como tampoco logra disminuir los riesgos para su vida y su salud.

La organización Advocates for Youth realizó una compilación comparativa de estudios científicos que evaluaran programas de educación sexual y de prevención, con el fin de resaltar aquellos que realmente fueran exitosos en sus procedimientos y objetivos para prevenir embarazos en la adolescencia y contagio de infecciones de transmisión sexual, incluido el VIH/SIDA. ${ }^{31}$ De los 19 estudios evaluativos de programas de educación sexual, 16 se referían a programas de educación sexual integral y comple-

\footnotetext{
${ }^{28}$ Idem.

${ }^{29}$ Reuters (ebruary 1, 2005): "Teen sex increased after abstinence program. Texas study finds litle impact on sexual behavior, en www.msnbc.msn.com/id/6894568 [Recuperado el 11 de agosto de 2005].

${ }^{30}$ Véase Advocates for Youth, Transitions, Vol. 12, No. 13, March 2001, p. 10.

${ }^{31}$ Véase Advocates for Youth, Science and Success. Sex education and other programs that work to prevent teen pregnancy, HIV \& sexually transmitted infections, Advocates for Youth, Washington, DC, 2003.
} 
ta, los cuales incluían tanto a la abstinencia como la información sobre el uso del condón y de métodos anticonceptivos. La eficiencia de estos programas se evidencia en la reducción de los riesgos en el comportamiento sexual de las y los adolescentes, en la posposición de la edad de inicio de prácticas sexuales coitales, la reducción de prácticas sexuales sin protección, y el aumento en el uso de métodos anticonceptivos, el aumento de elecciones seguras para tener prácticas sexuales con protección, el aumento de prácticas monogámicas junto con un mayor uso de condón, incluso la reducción del número de embarazos en adolescentes y de contagios de $\mathrm{VIH} /$ SIDA. $^{32}$

En México se han realizado muy pocos estudios comparativos serios que permitan evaluar el impacto de los programas de educación sexual que se desarrollan en el país. Un ejemplo fue el estudio realizado por Cristina Pizzonia, José Aguilar y Luis Botello (1995) respecto al impacto del curso de educación sexual llamado "Gente Joven" que ofrece la Fundación Mexicana para la Planeación Familiar desde hace más de diez años. ${ }^{33}$ En ese estudio se encontró que "en cuanto al curso, cuando se verificó impacto, éste nunca fue espectacular” (Pizzonia, Aguilar y Botello, 1995, 23). Aunque sí se encontró que los mayores efectos se producen en dos ámbitos: en cuanto a las expectativas de vida, trabajo y postergación de la paternidad y la maternidad y en los niveles de conocimiento e información de los jóvenes. Una conclusión importante de este estudio es que "existe una desproporción enorme entre los objetivos de los proyectos en su conjunto y los logros de sus instrumentos" $(1995,23)$. Lo anterior enfatiza la relevancia de hacer más estudios de evaluación de impacto que permitan mejorar los programas de educación sexual en México.

Según Rodríguez et al. (1995), algunos estudios evaluativos de programas de educación sexual muestran que como uno de sus principales resultados se obtiene un aumento de la información. Estos autores señalan que cuando los programas de educación sexual contienen prácticas interactivas, el desarrollo de habilidades y ensayos sobre los comportamientos preventivos se ha mostrado que los adolescentes disminuyen su actividad

${ }^{32}$ El estudio documental incluye las referencias completas de los programas y las evaluaciones realizadas a cada uno, así como los criterios de selección de los programas y los indicadores de evaluación de efectividad. Véase nota anterior.

${ }^{33}$ José Aguilar, Luis Botello y Cristina Pizzonia, "El impacto del curso de educación sexual 'Gente Joven' en conocimientos, percepciones, actitudes y comportamiento de los jóvenes”, Ponencia presentada en la v Reunión Nacional sobre la Investigación Demográfica en México, realizada en la ciudad de México del 5 al 9 de junio de 1995. 
sexual y el número de parejas sexuales; aunado a esto, se reportan mejores intenciones para el uso del condón o un uso más continuo, sobre todo si se aumenta la autoestima y se propician expectativas placenteras en las mujeres, por el uso del condón. También se ha visto que si se promueve el sexo "más seguro" junto con el posponer la actividad sexual, en vez de la sola abstinencia, no aumenta la promiscuidad sexual. Se ha mostrado además que hay mayor uso del condón cuando los grupos a los que se les dio la educación sexual son de menor edad o entre los que aún no habían iniciado relaciones sexuales. ${ }^{34}$

Como se pude observar, las evaluaciones realizadas a programas de educación sexual integral han demostrado ser eficaces en brindar herramientas a las y los jóvenes en beneficio de su bienestar y la toma de decisiones en el ejercicio de sus derechos en torno a su vida sexual. Las actividades y programas iniciados desde el gobierno federal de Ernesto Zedillo de alguna manera continúan desarrollándose actualmente y tienen su fundamento legal en la Constitución Política de los Estados Unidos Mexicanos, que en su artículo $3^{\circ}$ afirma: "Todo individuo tiene derecho a recibir educación.” En su contenido, los párrafos de este artículo establecen la obligación del Estado de impartir educación que permita desarrollar armónicamente todas las facultades del ser humano, su amor a la patria y su conciencia de la solidaridad en la independencia y la justicia. En las fracciones de este artículo se dispone que la educación debe ser laica y deberá estar basada en el progreso científico. Asimismo, el artículo $4^{\circ}$ constitucional postula: "El varón y la mujer son iguales ante la Ley" y que toda persona tiene derecho a decidir de manera libre, responsable e informada sobre el número y el espaciamiento de sus hijos, así como tiene derecho a la protección de la salud. Este artículo afirma que los niños y las niñas tienen derecho a la satisfacción de sus necesidades de salud y educación para su desarrollo integral.

El marco legal nacional que sustenta el derecho a la educación sexual integral también se localiza en la Ley General de Educación, la Ley General de Salud, así como la Ley General de Población, Ley Federal para la Protección de los Derechos de Niñas, Niños y Adolescentes y la Ley Federal para Prevenir y Eliminar la Discriminación. En el marco jurídico de la educación impartida por el Estado se define que la educación debe

\footnotetext{
${ }^{34}$ Véase Gabriela Rodriguez, Ana Amuchástegui, Martha Rivas y Mario Bronfman, "Mitos y dilemas de los jóvenes en tiempos del sida”, en Sida en México. Migración, adolescencia y género, Información Profesional Especializada, México, 1995, pp. 91-201.
} 
contribuir al desarrollo integral del individuo, para que ejerza plenamente sus capacidades humanas, con lo que la educación sexual integral es compatible en la medida en que posibilite el desarrollo de la persona y la prevención de situaciones que lo limite. ${ }^{35}$ Particularmente, la Ley General de Educación establece que la educación impartida por el Estado debe orientarse a desarrollar actitudes solidarias en los individuos, para crear conciencia sobre la preservación de la salud, la planeación familiar y la paternidad responsable. ${ }^{36}$

Por su parte, el marco jurídico de los servicios y la atención a la salud establece que el derecho a la protección de la salud tiene varias finalidades, entre las cuales incluye "la del bienestar físico y mental del hombre, para contribuir al ejercicio pleno de sus capacidades y el mejoramiento de la calidad de la vida humana". ${ }^{37}$ Si la salud reproductiva ha sido definida como "un estado general de bienestar físico, mental y social, y no de mera ausencia de enfermedades o dolencias, en todos los aspectos relacionados con el sistema reproductivo y sus funciones y procesos", ${ }^{38}$ la educación sexual integral es un elemento fundamental para su protección. En el artículo 3, la Ley General de Salud define como materia de salubridad general la educación para la salud, la planificación familiar, así como la prevención y el control de enfermedades transmisibles, por lo que fundamenta legalmente el derecho a la educación sexual integral.

En su artículo 67, esta ley federal establece que la planificación familiar es prioritaria y en sus actividades deberá incluir información y orientación educativa para adolescentes y jóvenes, además de que confirma la obligación de informar a las mujeres y los hombres sobre la inconveniencia del embarazo antes de los 20 años y después de los 35, ofreciendo información oportuna, eficaz y completa sobre métodos anticonceptivos. En el artículo 68, esta ley señala que los servicios de planificación familiar involucran el desarrollo de programas en esta materia.

En el ámbito legislativo federal también la Ley General de Población determina que la Secretaría de Gobernación deberá realizar programas de planeación familiar a través de los servicios educativos y de salud pública, vigilando que se desarrollen con total respeto a los derechos fundamenta-

\footnotetext{
${ }^{35}$ Véase Ley General de Educación, artículos 2, 5, 6, 7.

${ }^{36}$ Véase, Ley General de Educación, artículo 7 fracción x.

${ }^{37}$ Véase Ley General de Salud, artículo 2.

${ }^{38}$ María José Alcalá, Compromisos para la salud y los derechos sexuales y reproductivos de todos.

Marco de acción, Family Care International, Nueva York, 1995, p. 16.
} 
les y preserven la dignidad de las familias, incluidos todos sus miembros. Asimismo, deberá desarrollar programas para promover la plena integración de la mujer al proceso económico, educativo, social y cultural ${ }^{39}$ Como herramienta fundamental para el mayor éxito de programas con estos fines, la educación sexual integral resulta indispensable y necesaria.

El derecho a la educación sexual integral abarca más allá de la sexualidad y la reproducción, incluyendo la necesidad del cuidado de sí mismo y de la prevención de situaciones perjudiciales para la persona, como pueden ser enfermedades, embarazos no previstos, etc. Al contribuir al pleno desarrollo de las facultades del ser humano, así como a la satisfacción de sus necesidades, la educación sexual es un derecho que posibilita el bienestar de las personas en toda su vida en tanto es la vía para proveerles información y herramientas para el desarrollo de habilidades y capacidades necesarias para tener una vida sexual libre y responsable. Así, como derecho humano, la educación sexual integral encuentra su basamento jurídico en el primer capítulo de la Constitución Política mexicana y las leyes federales de población y de salud y educación.

Violeta Bermúdez dice que los derechos humanos son "un conjunto de facultades e instituciones que en cada momento histórico concretan las exigencias de la dignidad, la libertad y la igualdad humanas" (Bermúdez, 1996). ${ }^{40}$ Como parte de la dignidad, la libertad y la igualdad humanas, la salud sexual y reproductiva resulta indispensable para el mejor desarrollo del ser humano y de su calidad de vida. Por eso la educación sexual integral también tiene fundamentos legales en los compromisos internacionales jurídicos que el gobierno mexicano ha contraído al haber firmado y ratificado en su Congreso de la Unión.

Es el caso del Pacto Internacional sobre Derechos Económicos, Sociales y Culturales, que en su artículo 13 confirma el derecho de toda persona a la educación dirigida hacia el pleno desarrollo de la personalidad humana y del sentido de su dignidad. Los estados firmantes de este pacto acuerdan que la educación debe habilitar a las personas y su participación social, promoviendo la comprensión, la tolerancia y la amistad entre las naciones y los grupos sociales independientemente de la raza, la etnia y la religión. La educación sexual integral contribuye al desarrollo del ser humano y al respeto de su dignidad. El Comité sobre Derechos Económicos, Sociales y

\footnotetext{
${ }^{39}$ Véase Ley General de Población, artículo 3, fracciones 11 y v.

${ }^{40}$ Véase Violeta Bermúdez, “¿Qué son los derechos sexuales?”, en Salud, derechos sexuales y reproductivos. Desde la perspectiva de los profesionales de la salud, Manuela Ramos, Lima-Perú, 1996.
} 
Culturales, que vigila el cumplimiento de este pacto, ha establecido que la educación es fundamental para la protección de las niñas y las mujeres frente a la explotación sexual y la explotación en el trabajo, así como en la promoción de la democracia y los derechos humanos. Además, ha establecido que el derecho a la educación tiene efectos positivos a lo largo de la vida del ser humano y potencializa el carácter interdependiente e indivisible de los derechos humanos. ${ }^{41}$

Por otra parte, la Convención Internacional sobre la Eliminación de todas las formas de Discriminación en contra de las Mujeres (CEDAW) determina, en su artículo 5, la necesidad de garantizar la educación familiar que incluya una comprensión adecuada de la maternidad como función social y el reconocimiento de la responsabilidad común de hombres y mujeres en cuanto a la educación y al desarrollo de sus hijos, en el entendido de que el interés de los hijos será la consideración primordial en todos los casos. Si el interés de los hijos considera responsablemente su necesidad de información y educación sexual para un mejor desarrollo, la CEDAW obliga a los estados parte a garantizarla y promoverla. Los estereotipos de género basados en la discriminación y desvalorización a las mujeres en todos los ámbitos de la vida, incluida la sexualidad, se pueden atacar y transformar a través de la educación sexual. Es por ello que el Comité que vigila la Convención Internacional sobre la Eliminación de todas las formas de Discriminación en contra de las Mujeres establece que los estados parte tienen la obligación de eliminar estos estereotipos de género que limitan el acceso a la educación de niñas y mujeres, ${ }^{42}$ por lo que la educación sexual integral resulta fundamental para el cumplimiento de esta ley internacional.

De igual manera, establece en su artículo 10 que los estados parte deben tomar las medidas apropiadas para eliminar la discriminación contra la mujer, asegurándole la igualdad de derechos con el hombre en cuanto a la educación. En particular, el inciso b) de este artículo confirma que el Estado debe garantizar el acceso a material informativo específico que contribuya a asegurar la salud y el bienestar de la familia, incluida la información y la asesoría para la planificación familiar.

Un tercer instrumento convencional internacional que fundamenta el derecho a la educación sexual es la Convención de los Derechos del Niño

${ }^{41}$ Véase, "Advocacy: advocacia cidadá pelos direitos humanos", Derechos sexuales y derechos reproductivos en la perspectiva de los derechos humanos, Río de Janeiro, Brasil: Advocacy-Fondo de Población de Naciones Unidas, 2003.

${ }^{42}$ Véase, “Advocacy: advocacia cidadá pelos direitos humanos”, Op. cit., pp. 92-93. 
(CDN). En el artículo 28 esta convención reconoce el derecho de niños y niñas a la educación y la obligación de tomar las medidas necesarias para impartirla. Asimismo, en el artículo 29 afirma que la educación impartida por el Estado debe garantizar el máximo desarrollo de la personalidad, las aptitudes y las capacidades mentales y físicas de las y los niños, además de inculcarles el respeto de los derechos humanos y las libertades fundamentales. También debe contribuir a la preparación del niño y la niña para llevar una vida responsable con comprensión, tolerancia, igualdad de los sexos, paz y amistad entre los pueblos y los diferentes grupos religiosos y étnicos, lo cual implica preparar a los niños y las niñas para ser personas respetuosas y tolerantes ante las diferentes preferencias, no sólo religiosas y culturales, sino también sexuales.

De acuerdo con el Comité que controla la cDN, la educación debe apoyarse en los principios de la no discriminación, particularmente en relación con la igualdad de género, así como en el de la participación del niño y la niña en la vida escolar. En el ámbito de los derechos sexuales, el Comité de la CDN ha dado diversas recomendaciones a estados miembros para que planifiquen y realicen campañas de educación dirigidas a promover la salud sexual y reproductiva, además de recomendar que la educación sexual se introduzca en las currículas nacionales escolares. ${ }^{43}$

La CDN también confirma el derecho del niño y la niña a la libertad de expresión, y establece que ese derecho incluye la libertad de buscar, recibir y difundir informaciones e ideas de todo tipo, sin consideración de fronteras, ya sea oralmente, por escrito o impresas, en forma artística o por cualquier otro medio elegido por el niño. ${ }^{44}$ De esta manera, los estados parte están comprometidos a garantizar a niños y jóvenes el ejercicio de ese derecho, asegurando su libertad de buscar y recibir información relativa a su cuerpo, su sexualidad, su autocuidado, la reproducción humana, la planificación familiar, la prevención de enfermedades, en suma, la información necesaria para su bienestar y desarrollo pleno.

La educación sexual integral desde la infancia también contribuye a la prevención de abuso sexual y de explotación sexual. Los gobiernos que han firmado y ratificado la cDN están comprometidos a proteger al niño contra todas las formas de explotación y abuso sexuales (Art. 34), lo que les obliga a realizar acciones para impedir estas problemáticas, incluyendo programas y acciones de educación sexual.

${ }^{43}$ Ibid., pp. 93-94.

${ }^{44}$ Véase Convención para los Derechos del Niño, artículo 13. 
Como parte del marco legal que fundamenta el derecho a la educación sexual, también se encuentran los documentos convencionales regionales como la Convención Americana sobre Derechos Humanos, también llamada Pacto de San José de Costa Rica, donde se confirma el derecho a la libertad de expresión y pensamiento, incluida la libertad de buscar, recibir y difundir información de todo tipo; además de que establece que para el desarrollo progresivo los estados parte se comprometen a tomar las medidas y acciones necesarias para lograr la plena efectividad de los derechos económicos, sociales y sobre educación, ciencia y cultura, contenidos en la Carta de la Organización de los Estados Americanos, reformada por el Protocolo de Buenos Aires. ${ }^{45}$

El Protocolo Adicional a la Convención Americana sobre Derechos Humanos en Materia de Derechos Económicos, Sociales y Culturales, llamado Protocolo de San Salvador, confirma el derecho a la salud entendida como el disfrute del más alto nivel de bienestar físico, mental y social, y compromete a los estados parte a reconocerla como un bien público y a adoptar medidas que garanticen ese derecho, como es el caso de la educación de la población para la prevención y tratamiento de los problemas de salud, que incluyen los relacionados con la salud sexual y reproductiva. Asimismo, reconoce el derecho a la educación y el derecho a los beneficios de la cultura, y compromete a los estados parte a orientar la educación hacia el pleno desarrollo de la persona y garantizar que todas las personas gocen de los beneficios del progreso científico y tecnológico, lo que incluye a los beneficios que otorgan los métodos modernos de anticoncepción y prevención de ITs. Este protocolo también reconoce el derecho a la constitución y protección de la familia, en el que incluye la obligación de los estados parte a adoptar medidas especiales de protección de los adolescentes buscando garantizar la plena maduración de sus capacidades físicas, intelectuales y morales, para lo cual es necesaria la educación sexual integral. ${ }^{46}$

Finalmente, también se considera como marco jurídico de la educación sexual a la Convención Interamericana para Prevenir, Sancionar y Erradicar la Violencia contra la Mujer, llamada Convención de Belem do Para. Al igual que la CEDAw, esta convención establece en sus artículos el derecho a la no discriminación y la no violencia, y la obligación de los estados parte a garantizar las condiciones para erradicar, prevenir y sancionar la violen-

${ }^{45}$ Véase Pacto de San José de Costa Rica, artículos 13 y 26.

${ }^{46}$ Véase Protocolo de San Salvador, artículos 10, 13, 14 y 15. 
cia contra las niñas y las mujeres, con acciones en el ámbito de la salud y la educación, incluida la relativa a la sexualidad y la reproducción.

Tanto los instrumentos de derechos humanos internacionales como los del Sistema Interamericano de Derechos Humanos previamente citados, son fuentes de los derechos sexuales y los derechos reproductivos que avalan y protegen los derechos de las y los niños, adolescentes y jóvenes, de recibir información y educación sexual. ${ }^{47}$ Este marco legal fundamenta el derecho a la educación sexual integral en México, aun y cuando resulte necesario ampliarlo y adecuarlo a las necesidades de la población en esta materia, especialmente las de niñas, niños, adolescentes y jóvenes.

Actualmente la educación sexual integral no es una política pública generalizada en el gobierno mexicano. Sin embargo, los programas nacionales en materia de salud reproductiva, equidad de género, infecciones de transmisión sexual y VIH/SIDA reconocen la necesidad de la educación sexual integral y establecen objetivos específicos para desarrollarla. Es tarea pendiente la evaluación de los logros, alcances y limitaciones de dichos planteamientos, así como la planeación y desarrollo de más y mejores acciones de política pública en materia de educación sexual como parte de la educación general impartida por el gobierno.

\section{v. Consideraciones finales}

El derecho sexual a la educación sexual científica, confiable y laica, en México se ha impulsado y desarrollado en un trabajo colaborativo interinstitucional entre organizaciones gubernamentales, civiles y académicas, especialistas en el rubro. Se ha fundamentado a través de estrategias basadas en estudios científicos, materiales de vanguardia producidos y validados en América Latina, para brindar una educación sexual efectiva a niños, adolescentes y jóvenes. En colaboración permanente se ha avanzado en que el tema se incorpore poco a poco como parte de las políticas públicas para el ejercicio de sus derechos sexuales en el campo de la educación sexual y prevención, así como de atención integral a la salud sexual de adolescentes y jóvenes. ${ }^{48}$ Así, las escuelas públicas incorporan en sus programas algunas actividades de información y educación sexual, sobre

\footnotetext{
${ }^{47}$ Véase, "Advocacy: advocacia cidadá pelos direitos humanos", $0 p$. cit.

${ }^{48} \mathrm{Al}$ respecto, véase el texto de Gabriela Rodríguez, ¿Cuáles son los beneficios de la educación sexual? Carpeta informativa sobre los beneficios de la educación sexual en México, Red Democracia y Sexualidad, México, s/f.
} 
todo, aquellas basadas en los contenidos de los libros de texto de primaria y secundaria. Por su parte, algunas escuelas privadas de todos los niveles educativos se están interesando cada vez más en ofrecer a sus estudiantes una educación sexual de calidad y eficiente aunque es un asunto que no está lo suficientemente documentado, investigado y evaluado en términos de impacto. Siendo la escuela uno de los espacios fundamentales para que las y los adolescentes y jóvenes reciban educación sexual, se pueden delinear algunas ideas a considerar para planear y desarrollar un programa escolar acorde con los adelantos científicos y el marco de los derechos humanos de este sector de la población. ${ }^{49}$

Fernando Savater dice: "El arte de poner el placer al servicio de la alegría, es decir, a la virtud que sabe no ir a caer del gusto en el disgusto, se le suele llamar desde tiempos antiguos Templanza. Se trata de una habilidad fundamental del hombre libre pero no está muy de moda: se le quiere sustituir por la abstinencia radical o por la prohibición policiaca." ${ }^{50}$ La educación sexual integral puede contribuir al desarrollo de la templanza de manera que las y los jóvenes vivan como seres humanos libres y responsables de sus decisiones en torno a su vida sexual.

Además, más allá de las valoraciones individuales respecto a la propia sexualidad, la realidad de la vida sexual de las y los jóvenes impone la responsabilidad de atender sus necesidades con educación sexual integral y con condiciones que les permitan el ejercicio libre de sus derechos sexuales, y en ese sentido vale hacer la consideración de que en México queda un gran recorrido por realizar en el campo de la legislación y reglamentación de servicios dirigidos a posibilitar el pleno ejercicio de los derechos sexuales. Está claro que las decisiones individuales en el ámbito de la vida sexual son personales, privadas y propias de cada sujeto, pero las condiciones para el ejercicio de las prácticas sexuales libres, responsables, respetuosas y sin repercusiones y perjuicios para nadie, constituyen el campo de trabajo para el Estado en tanto garante de los derechos sexuales y reproductivos, como derechos humanos, y en ese sentido, el marco legal actual resulta amplio y vasto como marco de sustento aunque se ve reducido y limitado en tanto no se avance en la elaboración de procedimientos

${ }^{49}$ En México, la Comisión Nacional de los Derechos Humanos avala como derechos de las y los jóvenes, el derecho a la información completa, científica y laica sobre la sexualidad, así como el derecho a la educación sexual y a servicios de salud sexual y salud reproductiva. Véase Cartilla de los derechos sexuales de las y los jóvenes de la $\mathrm{CNDH}$ y firmada por más de 80 organizaciones civiles.

${ }^{50}$ Fernando Savater, Ética para Amador. 
y reglamentos que sostengan la práctica efectiva de estos derechos en términos de educación, prevención, servicios de salud adecuados y calificados para las y los jóvenes, acceso efectivo a información veraz, laica y confiable sobre sexualidad, a métodos de anticoncepción y prevención de infecciones de transmisión sexual.

Asimismo, está en frente el reto de homologar las legislaciones estatales y locales en términos de lo avalado por la Constitución Política mexicana y lo avanzado por las leyes federales y los compromisos vinculatorios internacionales firmados y ratificados por el gobierno mexicano, en el campo de los derechos sexuales de las y los jóvenes. Como señala la Secretaría de Salud en el folleto Conoce tus derechos sexuales y reproductivos iEjércelos!, los derechos sexuales y reproductivos son parte de los derechos humanos y tanto la Constitución Política mexicana como la Ley General de Salud son sustento legal y los establecen de manera congruente con los tratados y acuerdos internacionales firmados por México, por lo que corresponde seguir desarrollando instrumentos jurídicos y normativos para que las y los jóvenes puedan conocerlos ampliamente y ejercerlos efectivamente.

Volver al Índice >> 